\title{
PERAN MEDIASI CAPAIAN FINANSIAL: PRAKTEK MANAJEMEN KEUANGAN DAN KEPUASAN FINANSIAL PEDAGANG BATIK DAN SOUVENIR DI PASAR BERINGHARJO YOGYAKARTA
}

\author{
Risal Rinofah; Pristin Prima Sari \\ Universitas Sarjanawiyata Tamansiswa, Jl.Kusumanegara No.121, 55165, Yogyakarta \\ Email: pristin.primas@ustjogja.ac.id
}

\begin{abstract}
Abstrak
Penelitian ini bertujuan untuk menyelidiki peran mediasi capaian keuangan pada hubungan antara praktik manajemen keuangan dan kepuasan keuangan Usaha Kecil (UKM) di Pasar Beringharjo di Yogyakarta. Penelitian ini menggunakan data primer dan random sampling. Penelitian ini menggunakan kuesioner dengan skala likert. Penelitian ini mengumpulkan data untuk responden di Pasar Beringharjo Daerah Istimewa Yogyakarta. Hasil dari penelitian ini adalah capaian finansial dapat menjadi mediator dalam hubungan antara praktik manajemen keuangan dan kepuasan finansial. Studi ini dapat digunakan untuk sosialisasi praktik manajemen keuangan untuk usaha kecil (UKM), untuk mengembangkan usaha kecil (UKM), untuk membuat keputusan dalam bisnis, terutama usaha kecil (UKM).
\end{abstract}

Kata kunci: Praktik manajemen keuangan, Capaian finansial, kepuasan finansial, Pasar Beringharjo

\section{Abstract}

This study aims to investigate the mediation role of financial experience on the link between financial management practice and financial satisfaction of Small Business Enterprise (SME) in Beringharjo Market in Yogyakarta. This study uses primary data and random sampling. This Study uses questionaire with likert scale. This study collects data to respondent in Beringharjo Market of Yogyakarta Special Region. The result of this study is financial experience can be mediator in the link between financial management practice and financial satisfaction. This study can be used to campaign financial management practice to small business entreprise (SME), to develop small business entreprise (SME), to make decision in business especially small business entreprise (SME).

Keyword: Financial management practice, financial experience, financial satisfaction, Beringharjo Market

\section{PENDAHULUAN}

Mengelola uang merupakan tindakan yang rutin dilakukan oleh setiap orang baik dalam keluarga maupun bisnis. Mengelola uang adalah bagaimana kita mengelola pendapatan untuk memenuhi semua kebutuhan dan keinginan kita. Namun, banyak orang yang belum menyadari pentingnya mengelola uang. Disamping itu, literatur maupun penelitian terdahulu yang 
membahas tentang pentingnya mengelola uang masih terbatas. Beberapa penelitian yang telah menemukan bukti empiris mengelola keuangan antara lain household financial management (Hilgert, Hogarth, \& Beverly, 2003), kepuasan keuangan dan kebahagiaan (Hayes, 2014), financial literacy dan kepuasan keuangan (Kirbiš \& Galić, 2016), program pendidikan keuangan (Hathaway \& Khatiwada, 2008), financial attitude dan bentuk pinjaman personal (Ibrahim \& Alqaydi, 2013), Money attitude (Dowling, Corney, \& Hoiles, 2009) dan financial literacy mahasiswa (Ronald \& Chen, 1998).

Praktek mengelola keuangan berkaitan dengan bagaimana kemampuan kita mengelola arus kas, mengelola kredit, mengelola tabungan dan mengelola investasi untuk mendapatkan capaian keuangan (Hilgert et al., 2003). Praktek mengelola keuangan bagi usaha kecil dikelompok menjadi tiga bagian adalah manajemen kas, manajemen kredit dan manajemen investasi. Usaha kecil harus dapat mengelola kas, kredit, dan investasi untuk menghasilkan kinerja keuangan yang baik. Kinerja keuangan dapat diukur dengan capaian dalam bidang keuangan. Seseorang yang mengelola keuangan dengan baik dan benar maka dapat menghasilkan capaian dalam bidang keuangan misalnya seseorang dapat membeli mobil, rumah, kios, emas dan lain sebagainya. Demikian juga mengelola keuangan pada usaha kecil. Usaha kecil yang dapat mengelola keuangan dengan baik dan benar maka dapat mencapai bisnis yang sukses misalnya memiliki mobil untuk mobilitas usaha, memiliki kios, memiliki banyak cabang toko dan lain sebagainya.

Penelitian terdahulu telah menemukan bukti empiris berkaitan dengan mengelola keuangan dan capaian keuangan. Seseorang yang mengelola keuangan dengan baik dapat menghasilkan keuangan yang sehat. Capaian keuangan dapat diartikan kesejahteraan yang dicapai. Capaian keuangan merupakan tingkat kesehatan finansial. Capaian keuangan yang baik maka kondisi keuangan dalam keadaan sehat (Joo S, 2004). Tingkat pertumbuhan keuangan yang semakin meningkat maka kesejahteraan seorang wirausaha juga meningkat (Pham, Talavera, \& Zhang, 2018).

Mengelola keuangan yang baik dan benar juga dapat meningkatkan kepuasan seseorang khususnya dalam bidang keuangan (Kirbiš \& Galić, 2016). Beberapa peneliti terdahulu telah mendefinisikan kepuasan keuangan antara lain kepuasan keuangan adalah kepuasan dengan kondisi keuangan terkini dan ukuran kebahagiaan seseorang ((Joo S, 2004), (Murphy, 2013), (Gerrans, Speelman C, 2014)) dan faktor yang dominan terhadap kepuasan keuangan adalah pendapatan yang dimediasi oleh aspirasi keuangan personal (Plagnol, 2011). Pengetahuan keuangan dan praktek mengelola keuangan memiliki pengaruh positif terhadap kepuasan keuangan. Perbedaan gender juga dapat mempengaruhi tingkat pengetahuan dan praktek dalam mengelola keuangan yang dapat mencapai tingkat kepuasan (Woodyard \& Robb, 2012). 
Seseorang yang memiliki kepuasan keuangan yang baik maka terdapat capaian keuangan yang telah dimiliki. Capaian keuangan dapat dimiliki apabila seseorang melakukan pengelolaan keuangan dengan baik dan benar (Gerrans dan Speelman, 2014). Hasil temuan terdahulu berkaitan dengan kepuasan keuangan adalah laki-laki memiliki tingkat kepuasan keuangan lebih tinggi daripada wanita (Kirbiš \& Galić, 2016) dan (Woodyard \& Robb, 2012). Studi empiris lain yang berkaitan dengan kepuasan keuangan adalah faktor penentu kepuasan keuangan (Gerrans, Speelman, \& Campiteli, 2014), perbedaan gender dalam kepuasan keuangan (Hira TK, 2000), financial literacy dan kepuasan keuangan (Kirbiš \& Galić, 2016), dan kondisi keuangan dan ukuran kebahagiaan (Murphy, 2013).

Sejumlah peneliti Indonesia terdahulu telah menemukan bukti empiris berkaitan dengan pengaruh pengetahuan dan praktek mengelola uang. Studi empiris praktek mengelola uang di Indonesia antara lain tingkat pendidikan keuangan dan praktek mengelola uang pada mahasiswa di Surabaya (Rusmawati, 2013), studi perilaku mengelola uang oleh masyarakat Surabaya (Kholilah \& Iramani, 2013), perilaku keuangan dan pendapatan orang tua (Herdjiono \& Damanik, 2016), manajemen keuangan dan kepuasan keuangan istri (Fitri Apriliana Hakim, Euis Sunarti, 2014) dan perilaku keuangan terhadap pengendalian diri dalam bidang keuangan pada mahasiswa di Jakarta berdasarkan teori perilaku perencanaan (Putra, 2017).
Keterbaruan dari penelitian ini adalah peran mediasi capaian keuangan dalam pengaruh praktek mengelola keuangan terhadap kepuasan keuangan usaha kecil. Penelitian ini merupakan pengembangan penelitian terdahulu berkaitan dengan praktek mengelola keuangan dengan menambahkan variabel kepuasan keuangan dan capaian keuangan.

Fokus penelitian dilakukan pada usaha kecil di Pasar Beringharjo Yogyakarta. Yogyakarta merupakan suatu daerah Provinsi di Indonesia dengan keanekaragaman budaya dan potensi wisata. Dengan kekayaan budaya dan alam sebagai eksplorasi wisata baik domestik dan mancanegara maka usaha kecil di Yogyakarta berkembang dengan cepat. Banyak produk yang telah dihasilkan oleh usaha kecil baik melalui desa wisata maupun secara digital. Untuk itu diperlukan investigasi berkaitan dengan praktek mengelola keuangan dan tingkat kepuasan keuangan usaha kecil di Yogyakarta agar usaha kecil di Yogyakarta semakin berkinerja dengan baik.

Berdasarkan pentingnya penelitian tentang praktek mengelola keuangan dan kepuasan keuangan bagi usaha kecil maka penelitian ini menginvestigasi bukti empiris peran mediasi capaian keuangan dalam pengaruh praktek mengelola keuangan terhadap kepuasan keuangan bagi usaha kecil di Yogyakarta.

Tujuan penelitian ini adalah untuk menguji empiris capaian keuangan dapat memediasi pengaruh 
e-ISSN : :2549-1555

Praktek mengelola keuangan dan financial technology terhadap kepuasan keuangan dan Praktek mengelola keuangan dapat mempengaruhi kepuasan keuangan usaha kecil di Yogyakarta. Manfaat Penelitian adalah Bagi usaha kecil dapat menjadi sumber referensi dalam mengelola keuangan untuk mendapatkan capaian keuangan yang memuaskan. Dengan adanya penelitian ini maka usaha kecil mengetahui cara mengelola keuangan dengan baik dan benar. Bagi Pemerintah dapat menjadi pemetaan bagi pemerintah dalam mengetahui kemampuan usaha kecil dalam mengelola keuangan. Selain itu juga dapat untuk merumuskan kebijakan yang berkaitan dengan kinerja keuangan dan kepuasan usaha kecil. Bagi Penelitian Selanjutnya dapat menjadi bahan referensi bagi penelitian selanjutnya yang berkaitan dengan manajemen keuangan usaha kecil. Dengan demikian literatur tentang manajemen keuangan usaha kecil dapat berkembang secara luas.

\section{Usaha Kecil Di Yogyakarta}

Yogyakarta dikenal sebagai daerah istimewa. Keistimewaan Yogyakarta terdapat pada keanekaragam budaya. Selain itu, Yogyakarta juga berkembang sebagai kota wisata. Terdapat banyak potensi alam untuk berwisata. Oleh karena itu, Yogyakarta menjadi pusat berkembangnya bisnis tidak terkecuali usaha kecil. Usaha kecil di Yogyakarta berkembang dengan cepat dan luas. Banyak terdapat usaha kecil yang bergerak di sektor industri kreatif seperti kaos lukis, batik lukis dan batik tulis. Jumlah Usaha Mikro, Kecil Dan Menengah (UMKM) di
Yogyakarta sebanyak 13.998 unit usaha pada tahun 2010. Usaha kecil tersebut menggerakkan ekonomi kerakyatan. Sebagai kota tujuan wisata maka usaha kecil tumbuh dengan pesat. Kota wisata juga mendorong kesejahteraan usaha kecil.

Fokus penelitian dilakukan di Pasar Beringharjo Yogyakarta. Pasar Beringharjo merupakan pasar tertua di Yogyakarta. Pasar Beringharjo terlaetak di jalan Malioboro. Kawasan Malioboro merupakan kawasan wisata yang paling terkenal di Yogyakarta. Letak yang strategis merupakan daya tarik bagi wisatawan yang ingin berbelanja di Pasar Beringharjo. Pasar Beringharjo terletak dekat dengan Keraton Yogyakarta dan Stasiun Tugu. Aneka pakaian dan makanan dijual di Pasar Beringharjo. Terdapat banyak pedagang di Pasar Beringharjo antara lain batik, jilbab, aksesories, souvenir, jajanan pasar, uang kuno, pakaian anak dan dewasa, makanan cepat saji, bahan dasar jamu tradisional, sembako hingga barang antik.

\section{Kepuasan Keuangan}

Kepuasan keuangan adalah perasaan puas seseorang terhadap hasil yang dicapai dalam bidang keuangan. Selain itu dapat pula diartikan bahwa kepuasan keuangan merupakan rasa puas terhadap pendapatan yang diterima. Kepuasan keuangan adalah konsep penting untuk pengembangan masyarakat sebagaimana ditunjukkan yang dikaitkan dengan pilihan konsumen, produktivitas kerja, stress, dan pilihan sosial (Joo S, 2004). Temuan selanjutnya adalah wanita cenderung memiliki tingkat kepuasan keuangan 
yang rendah daripada laki-laki (Hira TK, 2000). Faktor penentu kepuasan keuangan di Amerika Serikat adalah pendapatan yang dimediasi oleh aspirasi keuangan individu (Plagnol, 2011). Lebih lanjut, kepuasan keuangan orang dewasa lebih tinggi daripada orang usia muda. Kepuasan keuangan juga berdasarkan jumlah hutang dan aset. Kepuasan keuangan berkaitan dengan kepuasan terhadap aset yang dimiliki dan kondisi keuangan terkini (Kirbiš \& Galić, 2016).

Kepuasan keuangan dipengaruhi oleh tingkat pengetahuan seseorang dalam bidang keuangan dan praktek mengelola keuangan. Gender memiliki pengaruh terhadap tingkat kepuasan, pengetahuan dan praktek keuangan (Woodyard \& Robb, 2012). Kepuasan keuangan berkaitan dengan tingkat kesejahteraan keuangan maupun kondisi keuangan yang baik. Kepuasan keuangan berkaitan dengan kebahagiaan seseorang dalam bidang keuangan (Murphy, 2013) dan (Gerrans, Speelman C, 2014).

\section{Capaian Keuangan}

Capaian keuangan adalah capaian yang telah didapatkan oleh usaha kecil. Capaian keuangan antara lain adalah benda bergerak maupun non bergerak yang telah berhasil dimiliki oleh usaha kecil. Capaian keuangan dapat disebut juga dengan financial experience (Hilgert et al., 2003). Capaian keuangan merupakan ukuran kesehatan finansial. Capaian keuangan yang tinggi maka akan menurunkan tingkat kesulitan keuangan (Joo S, 2004). Terdapat hubungan antara capaian keuangan dan pengelolaan uang (Gerrans $\mathrm{P}$, Speelman C, 2014).

\section{Praktek Mengelola Keuangan}

Praktek mengelola keuangan berkaitan dengan bagaimana kemampuan kita mengelola arus kas, mengelola kredit, mengelola tabungan, mengelola investasi, dan untuk mendapatkan financial experience (Hilgert et al., 2003). Praktek mengelola keuangan juga berkaitan dengan kemampuan kita dalam mengetahui dan mengenali produkproduk keuangan atau sering dikenal sebagai perilaku keuangan (Ibrahim \& Alqaydi, 2013). Mengelola uang juga berkaitan dengan praktek mengelola uang atau sikap dan perilaku kita terhadap uang (Kirbiš \& Galić, 2016), (Plagnol, 2011), dan (Chowa, Despard, \& Osei-Akoto, 2012). Mengelola keuangan dipengaruhi oleh tingkat pendidikan keuangan mahasiswa di Unesa (Rusmawati, 2013). Perilaku keuangan berkaitan dengan pengendalian diri dalam bidang keuangan (Putra, 2017). Mengelola uang meliputi perencanaan, penganggaran, pelaksanaan sampai pengawasan (Kholilah \& Iramani, 2013). Seseorang yang memiliki pengetahuan keuangan yang baik maka dapat mengelola keuangan yang baik pula. Pengetahuan keuangan berpengaruh positif terhadap praktek mengelola keuangan (C. a Robb \& Woodyard, 2011). Dalam penelitian ini praktek mengelola keuangan difokuskan dalam tiga aspek yaitu manajemen kas, manajemen kredit dan manajemen investasi. 


\section{Manajemen Kas}

Manajemen kas adalah cara mengelola arus kas antara lain kas masuk dan kas keluar. Dengan kata lain, manajemen kas adalah mengelola pendapatan yang diterima dengan pembelanjaan pendapatan. Aspek yang dinilai adalah bagaimana kemampuan usaha kecil dalam mengelola seluruh pendapatan yang diterima dengan semua kebutuhan. Manajemen kas adalah cara mengelola uang mulai dari perencanaan sampai pengendalian dan pengawasan (Hilgert et al., 2003). Mengelola kas juga dapat berkaitan dengan perilaku pengeluaran seseorang seperti perilaku belanja dan kecenderungan menggunakan pendapatan dalam jangka pendek maupun jangka panjang. Mengelola kas adalah perilaku mengelola uang dengan kecenderungan dihabiskan atau untuk kesenangan pribadi maupun untuk pendanaan jangka panjang (Kirbiš \& Galić, 2016).

\section{Manajemen Kredit}

Manajemen kredit adalah cara mengelola pendapatan untuk memenuhi tagihan hutang dari usaha kecil. Dapat diartikan pula, bagaimana usaha kecil dapat membayar cicilan hutang secara rutin dan tepat waktu. Manajemen kredit adalah mengelola hutang dan tagihan (Hilgert et al., 2003). Manajemen kredit yang baik adalah dapat membayar tagihan kredit rutin dan tepat waktu, memiliki perencanaan dan skala waktu yang baik dalam kredit. Praktek mengelola kredit dapat berkaitan dengan penggunaan kartu kredit dalam bisnis maupun keluarga. Terdapat pengaruh positif praktek mengelola keuangan dan perilaku penggunaan kartu kredit bagi mahasiswa (C. A. Robb \& Sharpe, 2009). Sikap dan perilaku keuangan seseorang memiliki pengaruh terhadap bentuk pinjaman seperti pinjaman bank, kartu kredit dan pinjaman teman (Ibrahim \& Alqaydi, 2013).

\section{Manajemen Investasi}

Manajemen investasi adalah cara mengelola pendapatan untuk belanja investasi. Kemampuan usaha kecil dalam membelanjakan pendapatannya untuk memilih instrumen investasi. Usaha kecil yang peduli investasi adalah usaha kecil yang dapat menganggarkan pendapatannya untuk produk-produk investasi seperti emas, saham, reksadana, deposito, dll. Penelitian terdahulu yang berkaitan dengan manajemen investasi adalah Manajemen investasi keluarga (Hilgert et al., 2003) dan perilaku keuangan bidang investasi (Kirbiš \& Galić, 2016). Manajemen investasi juga berkaitan dengan perencanaan terhadap kepemilikan investasi perumahan dan perencanaan pensiun (Volpe, Chen, \& Liu, 2006).

\section{Capaian Keuangan Memediasi Praktek mengelola keuangan Terhadap Kepuasan Keuangan}

Praktek mengelola keuangan yang baik dapat menghasilkan capaian keuangan. Capaian keuangan yang dimiliki dapat menimbulkan perasaan puas terhadap seseorang. Praktek mengelola keuangan yang baik dan benar dapat meningkatkan kepuasan dalam bidang keuangan. Peneliti terdahulu telah menemukan bukti empiris bahwa terdapat hubungan 
antara kesehatan keuangan personal dan kesejahteraan seseorang dengan literasi keuangan (Gerrans $P$, Speelman C, 2014). Praktek mengelola keuangan dapat memberikan dampak terhadap capaian keuangan (Hilgert et al., 2003). Perilaku dan sikap keuangan memiliki pengaruh terhadap tingkat kepuasan keuangan seseorang (Kirbiš \& Galić, 2016). Faktor penentu kepuasan keuangan adalah perilaku keuangan dan pengetahuan keuangan (Joo S, 2004). Hasil menunjukkan bahwa perilaku keuangan yang rasional memiliki tingkat tekanan keuangan (krisis keuangan) yang rendah dan pengetahuan keuangan yang tinggi dapat meningkatkan kepuasan keuangan. Berdasarkan temuan terdahulu maka hipotesis penelitian adalah sebagai berikut:

\section{Capaian keuangan dapat memediasi} Praktek mengelola keuangan Terhadap Kepuasan Keuangan

Pengelolaan keuangan yang baik dan benar maka dapat meningkatkan kepuasan keuangan seseorang. Hasil penelitian terdahulu menemukan bahwa perilaku keuangan dapat mempengaruhi kepuasan keuangan (Kirbiš \& Galić, 2016), praktek manajemen keuangan dan sikap keuangan berpengaruh terhadap masalah keuangan di Australia (Dowling et al., 2009). Topik keuangan berkaitan dengan model kepuasan (Brown, Durand, Harris, \& Weterings, 2014). Pengetahuan keuangan dapat menimbulkan kepuasan keuangan (Woodyard \& Robb, 2012) dan (Hira TK, 2000). Dengan demikian, praktek mengelola keuangan berpengaruh positif terhadap kepuasan keuangan.
Berdasarkan temuan terdahulu maka hipotesis penelitian adalah sebagai berikut:

Hipotesis: Praktek Mengelola Keuangan semakin besar maka dapat meningkatkan Kepuasan Keuangan

\section{Kerangka Pemikiran}

Berikut ini merupakan bagan pemikiran :

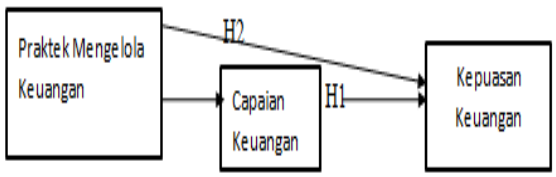

Gambar 2.1 Kerangka Pemikiran

Sumber : (Hiligert et al, 2003), |Kirbís \& Galic, 2016) (P Gerrans, Speelman C, 2014) dan (Ozili, 2018)

Gambar 1. Kerangka Pemikiran

\section{METODE}

Penelitian ini merupakan penelitian kualitatif. Penelitian kuantitatif adalah penelitian yang menggunakan data primer (Bougie, 2012). Data primer adalah data yang diambil dari orang pertama atau subyek penelitian.

\section{Subyek dan Obyek}

Subyek penelitian adalah usaha kecil di Pasar Beringharjo Yogyakarta. Obyek penelitian ini adalah praktik manajemen keuangan, capaian finansial dan kepuasan finansial. Usaha kecil yang menjadi sampel penelitian adalah usaha kecil yang bergerak dibidang pakaian dan souvenir. Lokasi pengambilan sampel adalah Pasar Beringharjo Yogyakarta.

\section{Teknik Sampling}

Pengambilan sampel dengan cara Teknik Random Sampling. Teknik random sampling adalah pengambilan sampel dengan cara acak (Lind, 
Marchal, \& Mason, 2012). $=111.998 /(1+1120)$

Pengambilan sampel dengan cara $=99,9$ sampel dibulatkan menjadi kuesioner yang dibagikan kepada 100 sampel.

responden.

Menurut Stolvin cara pengambilan sampel penelitian adalah :

$\mathrm{n}=\mathrm{N} /\left(1+\left(\mathrm{N} \times \mathrm{e}^{2}\right)\right)$

Keterangan :

n=Jumlah Sampel

$\mathrm{N}=$ Jumlah Populasi

$\mathrm{e}=$ tingkat kesalahan / error

Penelitian ini memiliki jumlah populasi sebanyak 111.998 usaha kecil di Yogyakarta. Dengan derajat kesalahan sebesar 10\% maka penghitungan jumlah sampel adalah sebagai berikut: $\mathrm{n}=111.998 /\left(1+\left(111.998 \times(0,1)^{2}\right)\right.$

Dengan demikian, sampel yang digunakan dalam penelitian ini adalah 100 unit usaha kecil.

\section{Variabel Kepuasan Keuangan}

Variabel kepuasan keuangan diukur dengan beberapa pertanyaan antara lain kepuasan terhadap kondisi keuangan terkini usaha kecil, aset bergerak, aset tidak bergerak dan kas yang dimiliki (Kirbiš \& Galić, 2016). Menggunakan ukuran skala likert 1-5 adalah angka 1 untuk sangat tidak setuju sampai angka 5 untuk sangat setuju.

Tabel 1. Kuesioner Kepuasan Finansial

\begin{tabular}{clc}
\hline No & \multicolumn{1}{c}{ Indikator } & Skor \\
\hline 1 & Apakah Anda Puas terhadap kondisi keuangan terkini & 12345 \\
2 & Apakah anda puas terhadap pendapatan yang diperoleh & 12345 \\
3 & Apakah anda puas terhadap benda tak bergerak yang anda miliki & 12345 \\
4 & Apakah anda puas terhadap kas yang anda pegang & 12345 \\
5 & Apakah anda puas terhadap barang bergerak yang anda miliki & 12345 \\
\hline
\end{tabular}

Sumber: Kirbiš \& Galić, 2016

\section{Financial Management Practice}

\section{1) Capaian Finansial}

Variabel capaian keuangan diukur dengan sejumlah benda yang dimiliki usaha kecil seperti rumah hak milik, mobil hak milik, motor hak milik, toko offline, emas batangan, perhiasan, smartphone (Hilgert et al., 2003). Menggunakan ukuran skala likert 1-5 adalah angka 1 untuk sangat tidak setuju sampai angka 5 untuk sangat setuju. Bentuk pertanyaan kuesioner adalah apakah Anda memiliki rumah sendiri, mobil hak milik, motor hak milik, toko offline, emas batangan, perhiasan, smartphone dan anak tidak putus sekolah / lulus sarjana.

Tabel 2. Kuesioner Capaian Finansial

\begin{tabular}{cll}
\hline No & \multicolumn{1}{c}{ Indikator } & Skor \\
\hline 1. & Punya smartphone & Yes No \\
2. & Membeli rumah (kontrakan / warisan) pilih salah satu & Yes No \\
3. & Mobil hak milik & Yes No \\
4. & Motor hak milik & Yes No \\
5. & Punya Toko offline diluar baik hak milik atau sewa & Yes No \\
6. & Anak lulus s1 / tdk putus sekolah & Yes No \\
7. & Memiliki emas batang & Yes No \\
\hline
\end{tabular}




\begin{tabular}{lll} 
8. & Memiliki Perhiasan & Yes No \\
9. & Pernah Renovasi Rumah & Yes No \\
\hline
\end{tabular}

Sumber: (Gerrans, Speelman C, 2014)

\section{2) Manajemen Kas}

Manajemen kas diukur dengan pengelolaan terhadap pengeluaran dan pendapatan yang dilakukan usaha kecil. Kegiatan mengatur kas adalah dapat membayar tagihan tepat waktu, dapat membayar pendidikan tepat waktu, dapat melakukan rekonsiliasi laporan keuangan secara rutin, dapat melakukan pendapatan, dapat membayar gaji rutin dan tepat waktu, dapat membayar pajak rutin dan tepat waktu (Hilgert et al., 2003). Menggunakan ukuran skala likert 1-5 adalah angka 1 untuk sangat tidak setuju sampai angka 5 untuk sangat setuju.

Tabel 3. Manajemen Kas

\begin{tabular}{clc}
\hline No & \multicolumn{1}{c}{ Indikator } & Skor \\
\hline 1. & Memiliki Aplikasi Mengecek akun Tabungan secara real time & 12345 \\
2. & Membayar Tagihan tepat waktu & 12345 \\
3. & Mencatat sistem keuangan atau pengeluaran biaya secara & 12345 \\
& rutin & \\
4. & Melakukan rekonsiliasi pencatatan keuangan setiap bulan & 12345 \\
5. & Menggunakan perencanaan anggaran / budgeting setiap & 12345 \\
& bulan & 12345 \\
6. & Menganggarkan biaya rekreasi secara rutin & 12345 \\
7. & Membayar biaya pendidikan tepat waktu & 12345 \\
8. & Keluarga saya sering makan diluar & 12345 \\
9. & Menganggarkan biaya Hari Raya tiap tahun & 12345 \\
10. & Menganggarkan CSR / dana sosial setiap bulan & 12345 \\
11. Membayar pajak rutin dan tepat waktu & 12345 \\
12. Membayar gaji karyawan rutin dan tepat waktu & 12345 \\
13. & Pendapatan saya banyak dari penjualan kredit
\end{tabular}

Sumber : (Hilgert et al., 2003)

\section{3)Manajemen Kredit}

Manajemen kredit diukur dengan dapat membayar tagihan kredit setiap bulan, mencatat laporan kredit secara teratur, membayar kredit tepat waktu dan teratur (Hilgert et al., 2003), dan memiliki tanggungan kredit lebih dari satu. Menggunakan ukuran skala likert 1-5 adalah angka 1 untuk sangat tidak setuju sampai angka 5 untuk sangat setuju.

Tabel 4. Manajemen Kredit

\begin{tabular}{clc}
\hline No & \multicolumn{1}{c}{ Indikator } & Skor \\
\hline 1 & Dapat Membayar tagihan kredit setiap bulan & 12345 \\
2 & Mencatat laporan kredit secara teratur & 12345 \\
3 & Saya dapat membayar kredit secara rutin tepat waktu & 12345 \\
4 & Memiliki tanggungan kredit lebih dari 1 item & 12345 \\
\hline
\end{tabular}

Sumber : (Hilgert et al., 2003) 


\section{4) Manajemen Investasi}

Manajemen investasi diukur dengan kemampuan usaha kecil dalam membeli produk-produk investasi seperti emas / perhiasan, saham, deposito, dll (Hilgert et al., 2003). Menggunakan ukuran skala likert 1-5 adalah angka 1 untuk sangat tidak setuju sampai angka 5 untuk sangat setuju.

Tabel 5. Manajemen Investasi

\begin{tabular}{llr}
\hline No & \multicolumn{1}{c}{ Indikator } & Skor \\
\hline 1 & $\begin{array}{l}\text { Saya merupakan orang } \\
\text { yang suka berinvestasi }\end{array}$ & 12345 \\
& $\begin{array}{l}\text { Emas } \\
2\end{array}$ & $\begin{array}{l}\text { Saya merupakan orang } \\
\text { yang suka berinvestasi }\end{array}$ \\
& 12345 \\
3 & $\begin{array}{l}\text { saham1 } \\
\text { Saya merupakan orang } \\
\text { yang suka menyimpan } \\
\text { uang deposito }\end{array}$ \\
\hline
\end{tabular}

Sumber: (Hilgert et al., 2003)

\section{Teknik Analisis Data Uji Reliabilitas}

Uji Reliabilitas adalah pengukuran instrumen bahwa konsisten terhadap pengukuran berdasarkan waktu dan silang situasi (Bougie, 2012). Analisis reliabilitas adalah analisis yang digunakan untuk mengukur konsistensi internal dalam instrumen pengukuran yang digunakan. Uji reliabilitas menggunakan nilai cronbach alpha. Nilai cronbach alpha lebih dari 0,07 maka instrumen tersebut dapat diandalkan.

\section{Uji Validitas}

Uji Validitas adalah untuk mengukur seberapa baik pengukuran instrumen tersebut (Bougie, 2012). Suatu instrumen harus valid dan dapat dipercaya/diandalkan.

\section{Analisis Regresi Uji Efek Mediasi}

Efek mediasi merupakan hubungan antara variabel independen (prediktor) dengan variabel dependen melalui variabel penghubung atau mediasi. Dengan kata lain, pengaruh variabel independen terhadap dependen bisa secara langsung atau melalui perantara (mediasi). Terdapat tiga langkah pengujian efek mediasi yaitu (Bougie, 2012) dan (Lind et al., 2012) :

a. Menguji efek utama $X$ ke $Y$ (variabel independen ke dependen), signifikansi 0,05.

b. Menguji variabel independen terhadap variabel mediasi ( $X$ ke M), signifikansi 0,05. Pengaruh variabel independen terhadap dependen

c. Menguji variabel mediasi dengan variabel dependen ( $\mathrm{M}$ ke $\mathrm{Y}$ ), signifikansi 0,05.

\section{Uji Hipotesis}

Uji hipotesis merupakan uji yang dilakukan untuk menjawab hipotesis penelitian. Uji hipotesis menggunakan uji $F$ (Anova) dan Uji t. Uji hipotesis diterima apabila nilai signifikansi 0,05 (Bougie, 2012).

\section{HASIL DAN PEMBAHASAN}

1.1 Deskripsi Statistik

Tabel 6. Profil Responden

\begin{tabular}{lcc}
\hline \multicolumn{3}{c}{ Jenis Kelamin } \\
\hline Laki-Laki & 17 & $19,3 \%$ \\
Perempua & 40 & $80,7 \%$ \\
& & \\
Jumlah & 57 & $100 \%$ \\
\hline \multicolumn{3}{c}{ Pendidikan } \\
\hline Sarjana & $\mathbf{1 1}$ & $19,3 \%$ \\
SMA & 46 & $70,1 \%$ \\
Jumlah & 57 & $100 \%$ \\
\hline
\end{tabular}


Tabel 6 menunjukkan profil Batik dan Souvenir. Mayoritas responden pedagang Pasar responden penelitian adalah Beringharjo. Responden berjumlah 57 perempuan dan berpendidikan pedagang yang terdiri dari pedagang sekolah menengah atas (SMA).

Tabel 7. Skor Kuesioner Responden

\begin{tabular}{lll}
\hline & Nilai Rata-rata & \% ( dari 100\%) \\
\hline Praktek Mengelola Finansial & - & \\
$\quad$ Manajemen Kas & 45,35 & $64,7 \%$ \\
$\quad$ Manajemen Kredit & 15,38 & $76 \%$ \\
$\quad$ Manajemen Investasi & 9,15 & $61 \%$ \\
Capaian Finansial & 25 & $57,58 \%$ \\
Kepuasan Finansial & 21 & $87,85 \%$ \\
\hline
\end{tabular}

Tabel 7 menunjukkan bahwa nilai manajemen kas usaha kecil pasar beringharjo sebesar 64,7; nilai manajemen kredit sebesar 76 dan nilai manajemen investasi sebesar 61. Nilai Capaian finansial responden sebesar 57,58 dan nilai kepuasan finansial sebesar 87,85. Usaha kecil belum menerapkan cek akun kredit dan arus kas secara online. Disamping itu, pedagang pasar beringharjo sangat ketat dalam mengelola keuangan sehingga tidak mengganggarkan banyak pengeluaran yang tidak penting.

\subsection{Praktek Manajemen Keuangan dan Capaian Keuangan}

Tabel 8. Model Summary ${ }^{b}$ Praktek Manajemen Keuangan dan Capaian Keuangan

\begin{tabular}{|l|c|r|r|r|r|}
\hline Model & $R$ & R Square & $\begin{array}{c}\text { Adjusted R } \\
\text { Square }\end{array}$ & $\begin{array}{c}\text { Std. Error of the } \\
\text { Estimate }\end{array}$ & Durbin-Watson \\
\hline 1 &, $592^{\mathrm{a}}$ &, 351 &, 314 & 6,32983 &, 980 \\
\hline
\end{tabular}

a. Predictors: (Constant), mankas, maninves, mankredit

b. Dependent Variable: capaian finansial

Tabel 8 menunjukkan bahwa Adjusted $R$ Square bernilai 0,314 maka variabel manajemen kas, manajemen investasi dan manajemen kredit dapat mempengaruhi variabel capaian

\begin{tabular}{|l|r|r|r|r|r|}
\hline \multicolumn{1}{|c|}{ Model } & Sum of Squares & \multicolumn{1}{c|}{ df } & Mean Square & F & \multicolumn{1}{c|}{ Sig. } \\
\hline 1 Regression & 1146,707 & 3 & 382,236 & 9,540 &, $000^{\mathrm{b}}$ \\
Residual & 2123,539 & 53 & 40,067 & & \\
Total & 3270,246 & 56 & & & \\
\hline
\end{tabular}

a. Dependent Variable: capaian finansial

b. Predictors: (Constant), mankas, maninves, mankredit 
Tabel 9 menunjukkan bahwa variabel manajemen kas, manajemen kredit dan manajemen investasi berpengaruh signifikan positif terhadap capaian finansial. Nilai $F$ menunjukkan angka 9,540 dengan nilai signifikansi sebesar 0,000 . Nilai signifikansi 0,000 lebih kecil dari 5\% maka Secara simultan variabel independen praktek mengelola finansial berpengaruh terhadap variabel dependen yaitu capaian finansial. Dengan demikian, Praktek Manajemen Keuangan yang baik dapat meningkatkan Capaian finansial atau kesejahteraan seseorang (Hilgert et al, 2003).

\section{Tabel 10 Coefficients ${ }^{a}$ Praktek Manajemen Keuangan dan Capaian} Keuangan

\begin{tabular}{|c|c|c|c|c|c|c|c|}
\hline \multirow[t]{2}{*}{ Model } & \multicolumn{2}{|c|}{$\begin{array}{l}\text { Unstandardized } \\
\text { Coefficients }\end{array}$} & \multirow{2}{*}{\begin{tabular}{|c} 
Standardiz \\
Coefficients \\
Beta
\end{tabular}} & \multirow[t]{2}{*}{$\mathrm{t}$} & \multirow[t]{2}{*}{ Sig. } & \multicolumn{2}{|c|}{$\begin{array}{l}\text { Collinearity } \\
\text { Statistics }\end{array}$} \\
\hline & B & Std. Error & & & & Tolerance & VIF \\
\hline $1 \quad$ (Constant) & 5,428 & 5,270 & & 1,030 & ,308 & & \\
\hline mankredit & ,722 & 169 & ,479 & 4,265 & ,000 & ,973 & 1,028 \\
\hline manves & 831 & ,250 & 373 & 3,331 & ,002 & ,975 & 1,026 \\
\hline mankas & ,052 & ,097 & ,060 &, 534 & ,596 & ,969 & 1,032 \\
\hline
\end{tabular}

a. Dependent Variable: capaian finansial

Tabel 10 menunjukkan angka $\mathrm{t}$ manajemen kredit sebesar 4,265 dengan nilai signifikansi sebesar 0,000. Angka 0,000 lebih kecil dari 5\% maka variabel manajemen kredit berpengaruh signifikan positif terhadap capaian finansial. Manajemen investasi memiliki nilai $\mathrm{t}$ sebesar 3,331 dengan nilai signifikansi sebesar 0,002. Angka signifikasi 0,002 lebih kecil dari 5\% maka variabel manajemen investasi berpengaruh signifikan positif terhadap capaian finansial. Variabel manajemen kas angka $t$ sebesar 0,534 dengan nilai signifikansi sebesar 0,534. Angka 0,534 lebih besar dari 5\% maka variabel manajemen kas berpengaruh signifikan positif terhadap capaian finansial.

\subsection{Praktek Manajemen Keuangan dan Kepuasan Finansial}

Tabel 11. Coefficientsa Praktek Manajemen Keuangan dan Kepuasan Finansial

\begin{tabular}{|c|c|c|c|c|c|c|c|}
\hline \multirow[b]{2}{*}{ Model } & \multicolumn{2}{|c|}{$\begin{array}{l}\text { Unstandardized } \\
\text { Coefficients }\end{array}$} & \multirow{2}{*}{\begin{tabular}{|c}
$\begin{array}{l}\text { Standardize } \\
\text { Coefficients }\end{array}$ \\
Beta \\
\end{tabular}} & \multirow[b]{2}{*}{$\mathrm{t}$} & \multirow[b]{2}{*}{ Sig. } & \multicolumn{2}{|c|}{$\begin{array}{l}\text { Collinearity } \\
\text { Statistics }\end{array}$} \\
\hline & $\mathrm{B}$ & Std. Error & & & & Tolerance & VIF \\
\hline (Constant) & 15,085 & 2,931 & & 5,147 & , 000 & & \\
\hline mankre &,- 042 & ,094 &,- 057 &,- 449 & 655, & 973 & 1,028 \\
\hline manves & 353 & 139, & 322 & 2,540 & 014 & ,975 & 1,026 \\
\hline mankas & ,092 & ,054 & 217 & 1,704 & 094 & ,969 & 1,032 \\
\hline
\end{tabular}

a. Dependent Variable: kepuasan

Tabel 11 Menunjukkan bahwa variabel manajemen kas berpengaruh signifikan positif terhadap variabel kepuasan finansial. Nilai signifikansi variabel manajemen kas sebesar 0,094 dengan nilai $t$ sebesar 1,704 . Nilai 0,094 lebih kecil dari $10 \%$ maka 
variabel manajemen kas berpengaruh berpengaruh signifikan terhadap signifikan terhadap kepuasan variabel kepausan finansial sebesar finansial. Variabel investasi 2,540. Variabel manajemen kredit berpengaruh signifikan positif memiliki signifikansi sebesar 0,655 terhadap variabel kepuasan finansial. dengan nilai $\mathrm{t}$ sebesar $-0,449$. Nilai Variabel investasi memiliki nilai 0,655 lebih besar dari 5\% maka signifikansi sebesar 0,014 dengan nilai variabel manajemen kredit tidak $\mathrm{t}$ sebesar 2,540. Nilai 0,014 lebih kecil berpengaruh terhadap kepuasan dari 5\% maka variabel investasi dapat finansial.

Tabel 12 ANOVAa Praktek Manajemen Keuangan dan Kepuasan Finansial

\begin{tabular}{|c|c|c|c|c|c|}
\hline Model & Sum of Squares & $\mathrm{df}$ & Mean Square & $\mathrm{F}$ & Sig. \\
\hline 1 Regression & 134,733 & 3 & 44,911 & 3,624 &, $019^{b}$ \\
\hline Residual & 656,846 & 53 & 12,393 & & \\
\hline Total & 791,579 & 56 & & & \\
\hline
\end{tabular}

a. Dependent Variable: kepuasan finansial

b. Predictors: (Constant), mankas, maninves, mankredit

Tabel 12 menunjukkan bahwa angka $F$ sebesar 3,624 dengan nilai signifikansi sebesar 0,019. Nilai 0,019 lebih kecil dari 5\% maka variabel manajemen kas, manajemen investasi dan manajemen kredit secara simultan berpengaruh terhadap kepuasan finansial. Hasil penelitian ini sama dengan penelitian Kirbiš \& Galić (2016) bahwa Praktek Manajemen Keuangan yang baik dapat meningkatkan Kepuasan Finansial. Hipotesis diterima.

Tabel 13 menunjukkan bahwa adjusted $R$ Square bernilai 0,123 artinya bahwa variabel independen manajemen kas, manajemen kredit, manajemen investasi dapat mempengaruhi variabel kepuasan finansial sebesar 12,3\%. Sedangkan sisanya sebesar $87,7 \%$ variabel dependen kepuasan finansial dapat dipengaruhi oleh variabel independen diluar model.

Tabel 13. Model Summaryb Praktek Manajemen Keuangan dan Kepuasan ransial

\begin{tabular}{|c|c|r|r|r|r|}
\hline Model & R & R Square & $\begin{array}{l}\text { Adjusted R } \\
\text { Square }\end{array}$ & $\begin{array}{l}\text { Std. Error of } \\
\text { the Estimate }\end{array}$ & Durbin-Watson \\
\hline 1 & 4133a $^{\mathrm{a}}$ &, 170 &, 123 & 3,52041 & 1,772 \\
\hline
\end{tabular}

a. Predictors: (Constant), mankas, maninves, mankredit 
b. Dependent Variable: kepuasan finansial

\subsection{Capaian Finansial Dan Kepuasan Finansial}

Tabel 14. Model Summaryb Capaian Finansial Dan Kepuasan Finansial

\begin{tabular}{|l|r|r|r|r|r|}
\hline Model & \multicolumn{1}{|c|}{$\mathrm{R}$} & $\mathrm{R}$ Square & $\begin{array}{c}\text { Adjusted R } \\
\text { Square }\end{array}$ & $\begin{array}{c}\text { Std. Error of the } \\
\text { Estimate }\end{array}$ & $\begin{array}{c}\text { Durbin- } \\
\text { Watson }\end{array}$ \\
\hline 1 &, $328^{\mathrm{a}}$ &, 108 &, 091 & 3,58397 & 1,718 \\
\hline
\end{tabular}

a. Predictors: (Constant), capaian finansial

b. Dependent Variable: kepuasan finansial

Tabel 14 menunjukkan bahwa adjusted $\mathrm{R}$ Square bernilai 0,091 artinya bahwa $9,1 \%$ variabel independen capaian finansial dapat mempengaruhi kepuasan finansial. Sedangkan sisanya sebesar 90,9\% dipengaruhi oleh variabel lain diluar model.

Tabel 15. ANOVAa Capaian Finansial Dan Kepuasan Finansial

\begin{tabular}{|l|r|r|r|r|c|}
\hline Model & Sum of Squares & \multicolumn{1}{|c|}{ df } & Mean Square & F & \multicolumn{1}{c|}{ Sig. } \\
\hline 1 Regression & 85,113 & 1 & 85,113 & 6,626 &, $013^{\mathrm{b}}$ \\
Residual & 706,466 & 55 & 12,845 & & \\
Total & 791,579 & 56 & & & \\
\hline
\end{tabular}

a. Dependent Variable: Kepuasan Finansial

b. Predictors: (Constant), capaian finansial

Tabel 15 menunjukkan bahwa variabel capaian finansial berpengaruh terhadap kepuasan finansial. Nilai F sebesar 6,626 dengan nilai signifikansi sebesar 0,013 . Nilai 0,013 lebih kecil dari 5\% maka variabel capaian finansial berpengaruh signifikan positif terhadap variabel kepuasan finansial. Hasil penelitian sama dengan Kirbiš \& Galić (2016) bahwa capaian finansial yang dicapai seseorang akan menimbulkan kepuasan finansial seseorang. Dengan demikian hipotesis diterima.

Tabel 16. Coefficientsa Capaian Finansial Dan Kepuasan Finansial

\begin{tabular}{|c|c|c|c|c|c|c|c|}
\hline \multirow[b]{2}{*}{ Model } & \multicolumn{2}{|c|}{$\begin{array}{c}\text { Unstandardized } \\
\text { Coefficients }\end{array}$} & \multirow{2}{*}{\begin{tabular}{|c} 
Standardized \\
Coefficients
\end{tabular}} & \multirow{2}{*}{$\mathrm{t}$} & \multirow{2}{*}{ Sig. } & \multicolumn{2}{|c|}{$\begin{array}{l}\text { Collinearity } \\
\text { Statistics }\end{array}$} \\
\hline & B & $\begin{array}{l}\text { Std. } \\
\text { Error }\end{array}$ & & & & Tolerance & VIF \\
\hline (Constant) & 17,566 & 1,728 & & 10,166 & ,000 & & \\
\hline ttlcapaian & 161 &, 063 & ,328 & 2,574 & ,013 & 1,000 & 1,000 \\
\hline
\end{tabular}

a. Dependent Variable: kepuasan Finansial

Tabel 16 menunjukkan angka $t$ sebesar 2,574 dan nilai signikansi sebesar 0,013 maka variabel capaian finansial berpengaruh signifikan

positif terhadap kepuasan finansial. Capaian finansial meningkat 1 satuan maka akan meningkatkan kepuasan finansial sebesar 2,574. 


\section{KESIMPULAN DAN SARAN Kesimpulan}

Penelitian bertujuan untuk menguji pengaruh peran mediasi capaian finansial terhadap pengaruh praktek mengelola finansial terhadap kepuasan finansial pada pedagang usaha kecil di Pasar Beringharjo. Penelitian menggunakan kuesioner kepada 57 pedagang batik dan souvenir di Pasar Beringharjo. Penelitian menggunakan SPSS 20 untuk mengolah data kuesioner. Hasil dari penelitian adalah variabel independen yang terdiri dari manajemen kas, manajemen investasi, dan manajemen kredit secara simultan berpengaruh signifikan positif terhadap kepuasan finansial. Variabel independen yang terdiri dari Manajemen kas, manajemen investasi, dan manajemen kredit secara simultan berpengaruh signifikan positif terhadap variabel mediator yaitu capaian finansial. Variabel independen capaian finansial berpengaruh terhadap kepuasan finansial. Dengan demikian, variabel capaian finansial dapat memediasi pengaruh praktek mengelola finansial yang diukur dengan variabel Manajemen kas, manajemen investasi, dan manajemen kredit.

\section{Saran}

Pedagang Pasar Beringharjo sudah memiliki smartphone sehingga pedagang hendaknya dapat menggunakan digital marketing untuk promosi kios di pasar beringharjo. Dengan demikian, penghasilan pedagang dapat meningkat. Bagi pemerintah, hendaknya menyelenggarakan event untuk meningkatkan semangat pedagang pasar beringharjo dan mempertahakan eksistensi keberadaan pasar beringharjo.

\section{DAFTAR PUSTAKA}

Billion, A. (2016). FinTech for micro, small and medium sized enterprises. ING Economic Department, (October).

Boonsiritomachai, W., \& Pitchayadejanant, K. (2018). Determinants affecting mobile banking adoption by generation $Y$ based on the Unified Theory of Acceptance and Use of Technology Model modified by the Technology Acceptance Model concept. Kasetsart Journal of Social Sciences, 1-10. https://doi.org/10.1016/j.kjss.20 17.10.005

Bougie, U. S. \& R. (2012). Research Method For Business: A Skill Building Approach. John Wiley $\mathcal{E}$ Sons Ltd, fifth Edit.

Brown, S., Durand, R. B., Harris, M. N., \& Weterings, T. (2014). Modelling financial satisfaction across life stages: A latent class approach. Journal of Economic Psychology, 45, 117-127. https://doi.org/10.1016/j.joep.2 014.09.001

Chowa, G. a N., Despard, M., \& OseiAkoto, I. (2012). Financial Knowledge and Attitudes of Youth in Ghana. Washington University in St. Louis Center for Social Development, 2, 1-7. Retrieved from https://csd.wustl.edu/Publicati ons/Documents/RB12-37.pdf

Dowling, N., Corney, T., \& Hoiles, L. 
(2009). Financial management practices and money attitudes as determinants of financial problems and dissatisfaction in young male Australian workers. ... of Financial Counseling and Planning ..., 20, 5-13. Retrieved from

http:/ / www.afcpe.org/assets/p df/vol20_2dowling_corney_hoil es.pdf

Fitri Apriliana Hakim, Euis Sunarti, T. H. (2014). MANAJEMEN KEUANGAN DAN KEPUASAN KEUANGAN ISTRI PADA KELUARGA DENGAN SUAMI ISTRI BEKERJA. Jurnal Ilmu Keluarga Dan Konsumen, 7(3).

Hathaway, I., \& Khatiwada, S. (2008). Do financial education programs work. Federal Reserve Bank of Cleveland.

Hayes, D. (2014). What is the Relationship between Financial Satisfaction and Happiness Among Older People? Personal Finance Research Centre. Retrieved from file:/ / C:/Users/hfarmer/Dow nloads/ILC_Financial_satisfactio n.pdf

Herdjiono, I., \& Damanik, L. A. (2016). Pengaruh Financial Attitude, Financial Knowledge, Parental Income Terhadap Financial Management Behavior. Jurnal Manajemen Teori Dan Terapan, 9(3), 226-241.

Hilgert, M. a., Hogarth, J. M., \& Beverly, S. G. (2003). Household Financial Management: The Connection between Knowledge and Behavior. Federal Reserve Bulletin, 106(November 1991), 309-322.

https://doi.org/10.1093/rfs/hh v072

Hira TK, M. O. (2000). Gender Differences In Financial Perception, Behavior, Satisfaction. Journal of Financial Counseling and Planning, 13(2), 86-92.

Ibrahim, M. E., \& Alqaydi, F. R. (2013). Financial Literacy, Personal Financial Attitude, and Forms of Personal Debt among Residents of the UAE. International Journal of Economics and Finance, 5(7), 126-138.

https://doi.org/10.5539/ijef.v5n $7 \mathrm{p} 126$

Joo S, G. J. E. (2004). An Exploratory Framework of The Determinants of Financial Satisfaction. Journal of Family and Economic Issues, 25(1), 25-50.

Kholilah, N. Al, \& Iramani, R. (2013). Studi Financial Management Behavior Pada Masyarakat Surabaya. Journal of Business and Banking, 3(1), 69-80.

Kirbiš, I. Š., \& Galić, Z. (2016). Relationship Between Financial Satisfaction and Financial Literacy: Exploring Gender Differences. STR, 305, 165-185. https://doi.org/10.5559/di.26.2. 02

L, M. J. (2013). Psychosocial Factors And Financial Literacy. Social Security Buletin, 73(1), 73-81.

Lind, D. A., Marchal, W. G., \& Mason. (2012). Statistical Techniques In 
Business and Economics.

Ozili, P. K. (2018). Impact of digital finance on financial inclusion and stability. Borsa Istanbul Review, 1-12. https:// doi.org/10.1016/j.bir.20 17.12.003

P Gerrans, Speelman C, G. C. (2014). The Relationship Between Personal Financial Wellness dan Financial Wellbeing: A Structural Equation Model Approach. Journal of Family and Economic Issues, 35(2), 145-160.

Pham, T., Talavera, O., \& Zhang, M. (2018). Self-employment, financial development, and wellbeing: Evidence from China, Russia, and Ukraine. Journal of Comparative Economics, (July), 01.

https://doi.org/10.1016/j.jce.20 18.07.006

Plagnol, A. C. (2011). Financial satisfaction over the life course: The influence of assets and liabilities. Journal of Economic Psychology, 32(1), 45-64. https://doi.org/10.1016/j.joep.2 010.10 .006

Putra, A. (2017). terhadap Self Control Behavior Dengan Theory Planned of Behavior. Akuntansi, 9(1), 1-19.

Robb, C. A., \& Sharpe, D. L. (2009). Effect of personal financial knowledge on college students' credit card behavior. Journal of Financial Counseling and Planning, 20(1), 25-43. Retrieved from https:/ / afcpe.org/assets/pdf/cl iff_a._robb_deanna_l.sharpe.pdf
Robb, C. a, \& Woodyard, A. S. (2011). Financial Knowledge and Best Practice Behavior. Journal of Financial Counseling and Planning, (205), 60-70. https://doi.org/10.1177/109019 8112463021

Ronald, P., \& Chen, H. (1998). An analysis of personal financial literacy among college students. Financial Services Review, 7(2), 107-128.

https:/ / doi.org/10.1016/S10570810(99)80006-7

Rusmawati, Z. (2013). Internalisasi Pendidikan Keuangan ke dalam Perilaku Manajemen Keuangan Mahasiswa Fakultas Ekonomi Universitas Negeri Surabaya. Jurnal Pendidikan Humaniora, 1(4), 343-353.

Volpe, R. P., Chen, H., \& Liu, S. (2006). An analysis of the importance of personal finance topics and the level of knowledge possessed by working adults. Financial Services Review, 15, 81-98. Retrieved from http:/ / www2.stetson.edu/fsr/a bstracts/vol_15_num1_p81.pdf

Woodyard, A., \& Robb, C. (2012). Financial Knowledge and the Gender Gap. Journal of Financial Therapy, 3(1), 0-16. https://doi.org/10.4148/jft.v3i1. 1453

www.umkm.jogjakota.go.id www.tribunjogja.com www.republika.co.id Yao, M., Di, H., Zheng, X., \& Xu, X. (2018). Impact of payment technology innovations on the 
Risal Rinofah, Peran Mediasi Capaian Finansial: Praktek Manajemen Keuangan dan Kepuasan Finansial Pedagang Batik dan Souvenir di Pasar Beringharjo Yogyakarta

ISSN : 1979-861X e-ISSN : :2549-1555

traditional financial industry: A

focus on China. Technological

Forecasting and Social Change,

(December 2017).

https:// doi.org/10.1016/j.techfo

re.2017.12.023 